\title{
Büyük Spor Organizasyonlarına Evsahipliği Yapmanın Avantajları ve Dezavantajları
}

\author{
Ali ÖZSOY \\ Bahar SENNAROĞLU*
}

\section{Öz}

$\mathrm{Bu}$ makale, kompleks projeler olan büyük spor organizasyonlarına ev sahipliği yapan ülke ve şehirlere bu organizasyonların yönetimsel, finansal ve sosyal etkilerinin değerlendirilmesini kapsamaktadır. Uluslararası büyük ve önemli spor organizasyonları günümüzde giderek daha büyük önem kazanmaktadır. Olimpiyatlar, Futbol Dünya ve Avrupa Şampiyonaları, Grand Slam Tenis müsabakaları, Formula One yarışmaları, basketbol, voleybol, handball gibi ana sporların Dünya ve Avrupa Şampiyonaları her yaştan seyirci ve izleyicilerin büyük ilgisini çekmektedir. Bu tür müsabaka ve yarışmaları organize etmek isteyen şehir ve ülkelerin sayısı giderek artmaktadır.

Herhangi bir sporu yöneten ve karar verme durumundaki kuruluşlara teklif verme ve adaylık dosyalarını sunma aşaması her zamankinden zorlu geçmektedir. Bununla beraber, büyük spor organizasyonlarına evsahipliği yapan şehir ve ülkelerin hedefleri, uygulamaları, aldıkları sonuçlar birbirinden çok farklı olmaktadır. Herhangi bir şehirde Olimpiyat düzenlenmesi bir şehrin kaderini olumlu yönde değiştirebilmekte, bir diğerinde ise etkisini uzun yıllar sürdürecek ekonomik çöküntülere neden olabilmektedir. Konuyla ilgili birbirine zıt, çok değişik görüşlerin ortaya atılması yanında yüksek bütçeler ve harcamaların etkilerinden bahsediyor olmamız konunun önemini arttırmaktadır. $\mathrm{Bu}$ çalışmanın amacı, aday olunan söz konusu organizasyonların, evsahibi şehir ve ülkeye ne getirip, ne götürdüğünü araştırmak, kısa ve uzun vadeli sosyal ve ekonomik etkilerini incelemektir. Sonuç olarak büyük spor organizasyonlarına ev sahipliği yapmanın avantajlarının, ortaya çıkan dezavantajlarına göre daha fazla olduğu değerlendirilmiştir.

Anahtar kelimeler: Büyük spor organizasyonları, ev sahipliği, proje

* Doktora Öğrencisi, Marmara Üniversitesi, Fen Bilimleri Enstitüsü, ozsoyali@hotmail.com

** Doç. Dr., Marmara Üniversitesi, Endüstri Mühendisliği Bölümü, bsennar@marmara.edu.tr 


\title{
Advantages and disadvantages of hosting large scale sports events
}

\begin{abstract}
This article aims to analyze and study the financial, social and managerial impacts of hosting large scale sports events, which are complex projects, for the host cities and countries. It is evident that the significance and the recognition of large scale sports events today have risen considerably. The Olympics, Football World and Europe Cups, Grand Slam Tennis Tournaments, Formula One and the World and European Championships of major sports as basketball, volleyball and handball attract the attention of audiences of all ages. Hence, the number of cities and countries bidding to host these events is in a significant rise. Presenting these host bids to the committees making the selections have grown to be an arduous task. In addition, the aims, execution and the results of the cities and countries hosting large scale sports events may turn out completely different from each other. While the success of hosting an Olympics may benefit and better the fate of the host city, it can also present itself to be a long lasting economic liability and concern.

The importance of the study comes from the impact of high budgets and spending as well as the variety of the perspectives being presented. The goal of this study is to analyze the benefits as well as the consequences in a short versus long term social and economic perspective for the cities and countries that have hosted these events. In conclusion, it has been evaluated that the advantages of hosting large scale sports events prove to outweigh the disadvantages that come along with them.
\end{abstract}

Keywords: Large scale sports events, hosting, project

\section{GíRiş}

Projeler, tanım olarak, kendilerine özgü, özel ve çoğunlukla oldukça karmaşık görevlerdir (Gray ve Larson, 2010). Belirlenmiş bir zaman içerisinde, talep ve planlamaya bağlı olarak insan, finansman, tesis, ekipman/malzeme ve diğer kaynaklar kullanılarak gerçekleştirilirler. Genel olarak, projelerin tanımlanmış amaç ve hedefleri vardır. İster günler boyu sürecek bir turnuva olsun, isterse tek maçlık bir final olsun, büyük ölçekli bir spor organizasyonu, bünyesinde birçok alt projeyi içeren büyük bir projedir. Değişik ülkelerden sporcular ve içinde bulundukları delegasyonlar, sonucu önceden kestirilemeyen bir yarışma içine girmekte; yönetim, planlama, pazarlama, risk, bütçeleme, tanıtım ve diğer faaliyetlerin gerçekleştiği, proje yönetiminin titizlikle uygulanmasını gerektiren bir organizasyonda yer almaktadırlar.

Büyük bir spor organizasyonunu alma ve yönetmenin, yeni bir şirket kurmaktan veya pazara yeni bir ürün sürmekten farkı yoktur. Organizasyonun önce ev sahipliği hakkının alınması, daha sonra da merkezi yönetim, katılımcılar, seyirciler, sponsorlar, dünyada o sporu yöneten ana kuruluş ve benzeri iştirakçilerin/paydaşların memnun edilmesi söz konusudur. Bu arada, ürünü pazara sunmak için gerekenler sırasıyla yapılmalı, mali hususlar dikkatle hesaplanmalıdır. İnsan kaynağı iyi yönetilmeli, riskler öngörülerek önlemler alınmalı ve pazarın nabzı tutularak son tüketicinin değişen beklentilerine uyum sağlayacak esneklik gösterilmelidir. Büyük spor 
organizasyonlarının yönetimi bilinen iş disiplinlerine bağlı olsa da, herhangi bir ürünün hazırlanıp piyasaya sürülmesinden çok daha karmaşıktır.

Büyük ölçekli spor organizasyonlarında ortaya proje, operasyon ve sportif riskler gibi birçok risk çıkabilir. Organizasyon komiteleri, salon/stadyum inşaatlarındaki gecikme ve maliyet artışlarından sağlık problemlerine, terör tehditlerinden enerji kesintilerine kadar çeşitli sorunlarla başa çıkmak zorunda kalabilirler (Jennings, 2013). Organizasyona katılan sporcu ve seyirciler için sağlıklı ve güvenli bir ortam yaratmak; tasarım, planlama ve operasyon aşamalarını buna göre yürütmek, doğru ve adil kararlar vererek kaynakları başarıyla yönetip, korumak artık birincil derece öneme sahiptir (Corbett, 2002). Spor organizasyonlarının proje yönetiminin temelini risk yönetimi oluşturmaktadır. Eski algılarda olduğu gibi risk yönetimi artık sadece şiddet ile sınırlı değildir ve kalabalık yönetimi, elverişsiz hava koşulları, organizasyonun iptal edilme olasılığı, yiyecek zehirlenmeleri, finansal kayıplar da dahil olmak üzere ortaya çıkabilecek tüm risk faktörlerini engellemek, etkilerini azaltabilmek ve hazırlıklı olabilmek için yapılacak planları kapsar (Loepkey ve Parent, 2007).

Matheson ve Baade (2004) tarafından da belirtildiği gibi önemli spor organizasyonlarını düzenlemek çok ciddi giderlere yol açmaktadır. Bazı yazarlara göre Olimpiyatlar gibi büyük spor organizasyonları için yapılan harcamalar elde edilecek yararların çok üzerinde olmaktadır (Ritchie, Shipway ve Cleeve, 2009). Son ylllardaki artan terör tehditleri nedeniyle de güvenlik harcamaları üst seviyeye çıkmıştır. Bazı yazarlar ise sosyal etkilerin ekonomik kayıpların çok ötesinde olduğunu iddia etmektedirler. Matos (2006) elde edilen artıları; ekonomik büyüme, sonraki nesillere kalan alt yapı-tesisler ve imaj iyileştirme olarak 'kutsal üçlü' şeklinde tanımlamaktadır. Bununla beraber söz konusu etkileri detaylı saptamak ve değerlendirmek kolay değildir, ayrıca 'başarı' değişik insanlara göre değişik anlamlar ifade etmektedir (Röfner ve Müller, 2009). Üstelik spor yönetimleri çoğunlukla sonuçlara bakmakta ve konunun sosyal ve kültürel getirileri ile pek ilgilenmemektedirler. Dolayısıyla, bazı şehir ve ülkelerin bekledikleri sonuçları alıp alamadıkları hep tartışma konusu olmuştur.

Ev sahiplerinin başarılı olabilmesi için; kısa değil uzun vadeli etkileri düşünmeleri, plan-program yapmaları, belli kaynaklara ve alt yapılara sahip olmaları, net bir strateji üzerinde anlaşmış bulunmaları, kısacası adaylık sürecinden başlayarak spor organizasyonun sonuna kadar tüm organizasyonu proje yönetiminin prensiplerine uygun olarak yürütmeleri gerekmektedir.

Nooij, Van den Berg ve Koopmans (2013) tarafından da belirtildiği gibi neredeyse tüm büyük spor organizasyonları için geçerli sayılabilecek üç önemli husus vardır:

- Organizasyonun finansal ve ekonomik getirileri maliyetleri karşılamakta güçlük çekmekte, bununla beraber ev sahibi ülke vatandaşları büyük bir mutluluk, gurur duymakta ve uyum içinde ulusal kimlik geliştirmektedirler.

- Artıya geçebilmek için ölçülü ve maliyetlere karşı hassas, işinin ehli bir Lokal Organizasyon Komitesi gereklidir.

- Maliyetler konusunda ciddi belirsizlikler vardır ve elde edilecek avantaj ve başarılar abartılmaktadır. 
Günümüzde giderek daha büyük önem kazanan uluslararası büyük ve önemli spor organizasyonlarına ev sahipliği yapan şehir ve ülkeler için bu organizasyonların avantaj ve dezavantajları bu çalışmanın sonraki bölümlerini oluşturmaktadır. Çalışmanın amacı, bu organizasyonların ev sahibi şehir ve ülkeye ne getirip, ne götürdüğünü araştırmak, kısa ve uzun vadeli ekonomik ve sosyal etkilerini incelemektir.

\section{Avantajlar}

Büyük spor organizasyonlarına ev sahipliği yapmanın avantajları; popularite ve ülke-şehir imajı, inşaat ve iş imkanları, turizm, özel sektörün ilgisinin çekilmesi, sosyal sorumluluk, sporun gelişimine etkisi, mutluluk ve gurur duyma, ulaşım ve telekomunikasyonun gelişmesi, ileriye dönük kalıcı tesisler bakımından incelenmiştir.

Popularite ve ülke-şehir imajı: Büyük spor organizasyonları şehir ve ülkelerin dünya haritasında belirgin bir şekilde ortaya çıkmalarına neden olmaktadır. Belki Londra’nın önemi ve değeri herkes tarafından biliniyordu ama 2014 Dünya Kupası̉na ev sahipliği yapan Güney Afrika hakkındaki algı olumlu yönde değişmiştir. 1980’lerde pek bilinmeyen Güney Kore, Olimpiyatlar sonrası dünyaya açılmış, kültürünü sergilemiş, dünya ekonomisine entegre olduğunu göstererek yabancı yatırımcıları çekmiştir. Tüm dünya 2000'de Avustralyadaki Aborjin kültürünü öğrenme fırsatını yakalamıştır. Çin bir ekonomik güç olduğunu Beijing 2008 Olimpiyatları sayesinde de göstermiştir. Tüm dünyanın gözünün üstünde olması, bir ülke için organizasyon sonrası yeni uluslararası iş olanaklarını ve dış sermaye akımını da beraberinde getirebilir.

Toplumun kendisi de kendisine biçtiği kimliği olumlu yönde değiştirebilir. Ayrıca, ziyaretçilere iyi bir izlenim verebilmek için ev sahipleri, cinayet, yoksulluk, şehirleşme vb. konuların üstüne gidip olumlu sonuçlar alabilirler. Büyük turnuvalar, insanların çevre ve yeşile duyarlık konularındaki düşünce ve davranış tarzlarını da etkileyebilir.

Inşaat ve iş imkanları: Önemli turnuvaların ev sahipliği için o sporun dünyadaki yönetici kurumu durumunda olan organizasyonlar ihale sürecini çok önceden başlatmakta ve kararlarını hedeflenen organizasyon tarihinden 6-7 yıl öncesinden açıklamaktadırlar. Bu da ev sahiplerine önemli bir planlama ve hazırlık süreci, bunun sonucunda da yatırımlar yapma ve iş imkanları oluşturma fırsatı vermektedir. Şampiyonanın boyut ve önemine göre sadece salon ve stadyumlar değil, ulaşım altyapıları, şehir düzenlemeleri, sporcular için konaklama tesisleri, yollar, metro, havaalanı ve otel yatırımları gerçekleşmektedir. Bu sayede iş imkanları oluşmakta ve ekonomik değer yaratılmaktadır.

Turizm: Büyük bir spor organizasyonuna ev sahipliği yapmanın bir şehri ve ülkeyi nasıl değiştirebileceğine en güzel örnek 1992 Olimpiyatları ve Barselona şehridir. Bugün dünyanın en ilgi gören şehirlerinden biri olan Barselona’da (Uluslararası Olimpiyat Komitesi-IOC’ne göre dünyada 11., Avrupa'da 5. en popüler şehir) değişim 1992'deki Yaz Olimpiyatları ev sahipliği ile başlamıştır. Deniz kıyısındaki endüstri tesis ve depolarının yıkılıp $3 \mathrm{~km}$. boyunda bir plaj ve büyük bir marina yapılması turistlerdeki Barselona algısını çok değiştirmiştir. Sadece turizm alanında değil, sporun gelişimi, iş imkanları yaratılması, alt yapılar ve tesisleşme konularında 
da Barselona bugüne kadarki en iyi örneklerden biridir. Barselona'da olanlar, daha sonraki ev sahiplerine ilham kaynağı olmuştur (IOC, 2012).

Özel sektörün ilgisinin çekilmesi: Büyük bir organizasyonun ev sahipliği hakkının alınması sorumluluğu her ne kadar devlet sektörü birimlerine düşse de, organizasyonun başarısı için özel sektörün de katılımının sağlanması şarttır. Adaylık sürecindeki çalışmalara, tesislerin mimari ve maliyet çalışmalarına özel sektör de davet edilmelidir. Devlet sektörü yönlendirici, gerekli yönetmelikleri çıkaran fonksiyonlara konsantre olurken, uygulamalar özel sektörden gelecektir.

Bu tip organizasyonlarda herkes tarafından bilinen kesin bitirme ve devreye alma tarihleri mevcuttur. Böyle yoğun ve teknik bilgi (know-how) gerektiren bir iş temposunun altından özel sektör kalkabilecektir.

Diğer taraftan, şampiyonaların gelir bölümündeki en önemli kalem, bilet satışlarıyla birlikte, sponsorluk ve reklam satışlarıdır. Günümüzde, pazarlama stratejilerinde spor pazarlamasının rolü giderek artmakta, spor sponsorluklarını seçen firmalar rakiplerine karşı üstünlük sağlamakta ve firmaların spora verdiği destek taraftar ve seyircilerde memnuniyet duygusu yaratmaktadır (Abiodun, 2011). Son 30 yılda pazarlama ve reklam sektöründe hiçbir alt başlık 'sponsorluk' kadar değişim ve gelişim göstermemiştir. Dünyada yıllık 110 Milyar Doların üstüne çıkan reklam sektöründe önceki yıllarda kim fazla harcarsa onun başarılı olacağı varsayılırdı. Günümüzde ise, insanlar daha az TV seyrettikleri ve seçenekleri arttığı için artık firmalar yöntem değiştirmek zorunda kalmaktadırlar. İlginç buluşlar, orijinallik artık bir seçenek değil, zorunluluk haline gelmiştir. Bu ortamda büyük spor turnuvalarına/müsabakalarına sponsor olmak iyi bir seçenek olmaktadır. İngiltere Futbol Ligi’ni TV'de izleyenlerin sayısının 4,7 Milyar ve ligi takip edenlerin attıkları tweet'lerde ana sponsor Barclays Bank ismini kullananların sayısının 30,9 Milyon olduğu göz önüne alındığında ne demek istendiği anlaşılacaktır (Brandwatch, 2013). Yerel Organizasyon Komitesinin uygulayacağı pazarlama ve tanıtım planlarının başarısı organizasyonun bütçe konusundaki başarısını da doğrudan etkileyecektir.

Sosyal Sorumluluk: Artık tipik bir firma toplumun/müşterilerinin ekonomik ve sosyal beklentilerini daha iyi karşılayabilmek için kurumsal değerlerini yaymak zorundadır (Ibrahim ve Almarshed, 2014). Sosyal Sorumluluk Projeleri şirket hissedarlarının karlılıklarının arttırılmasının çok üstünde, sosyal iyilikler gözetilerek yapılan programlardır. Kurumsal Sosyal Sorumluluk (KSS) artık modern kuruluşlarda iş konularına ek olarak, rakiplerle farklılıklarını gösterdikleri ve toplumla iletişim kurdukları önemli bir yan aktivite haline gelmiştir. Baron'un (2003) belirttiği gibi, bir şirketin performansı sadece ana iş dalında değil, pazar dışı ortamlarda gösterdiği performansa da bağlı olduğundan, KSS şirketlerin stratejilerinde çok önemli bir yer tutmaktadir.

Büyük ölçekli spor organizasyonları da bu tip Sosyal Sorumluluk Projelerinin başarıyla uygulanabileceği en uygun alanlardan biridir. Kamuoyu da spor organizasyonlarının yanındaki aktiviteleri; insancıl, etik ve ekonomik açıdan hem beklemekte, hem de istemektedir. Sosyal konularla ilintili oluşu ve toplum içindeki belirgin etkisi nedeniyle KSS ve spor birbirlerinin ayrılmaz bir parçası sayılabilirler (Walters ve Chadwick, 2009). 
Doğal olarak, spor gençlerin çok ilgisini çektiğinden, eğer bir Sosyal Sorumluluk Projesi spora bağlanmışsa çocukların katılımı kesinlikle artacaktır. Spor, fiziksel aktiviteyi kapsadığı için sağlıklı yaşam konseptini içine almakta, daha iyi ve sürdürülebir çevre koşullarını-bilincini anımsatmakta, son olarak da, maçların cazibesi ve uluslararası erişim gücü yüksek olduğundan yoğun medya dağıtımı ve iletişim gücünü temsil etmektedir. Sayılan bu nedenlerle büyük şampiyonalar, kaçınılmaz olarak Sosyal Sorumluluk Projelerini de yanlarında sürüklemektedirler.

Sporun Gelişsimine Etkisi: Her ne kadar Londra Olimpiyatları sonrası yapilan araştırmada (Sport England's Active People Survey) İngilizlerin spora bakış açılarının olumlu yönde değiştiğini gösteren çok az veri ortaya çıksa da, Coalter (2004) sporda elde edilen başarıların kitleleri hareketlendirdiğini ve o spor dalındaki katılımı arttırdığını gösteren bulguların eksikliğinden ve 'rol model' olarak kabul edilen sporcuların olası kötü örnek olabilecek yaşantılarından söz etse de; iyi tesis yatırımları ve büyük turnuvalarda alınacak başarılı sonuçlarla birlikte o spor dalına ilgi büyük oranda artacaktır. Türkiye’nin gümüş madalya aldığ 1 ve sadece finalde ABD’ye yenildiği 2010 FIBA Dünya Basketbol Şampiyonası sonrası ülke çapında basketbol okullarına katılım tam üç misli artmıştır. Dolayısıyla, sportif başarı ile spora katılım arasında pozitif yönlü bir ilişki vardır. Başarıya ek olarak sporcular spora olan ilgiyi daha da arttıracaktır. Spor bu şekilde, gençler arasında; ilginç, çekici, yarışmacı, ulaşılabilir ve ödüllendiren bir aktivite olarak algilanacaktır.

Mutluluk ve gurur duyma: Büyük organizasyonlara aday olmamak için bir sürü neden öne sürülebilir; yüksek maliyetler, ekonominin kötü gidişi ve borç içinde bulunma, önceliklerin başka projelere verilmesi gerektiği vb. Ancak, spor organizasyonun alınmasına müsabakalarda başarılı sonuçlar alınması da eklenirse, sadece bir veya birkaç şehri değil, ülkenin tamamını büyük bir heyecan ve mutluluk kaplamaktadır. İnsanlar, sporsever olsun olmasın, yarışmaları izlemekte, organizasyonun başarılı olması halinde milli bir gurur duymakta ve ülkeleriyle iftihar etmektedirler.

Ulaşım ve Telekomünikasyonun Gelişmesi: Ana/popüler sporların dünyadaki düzenleyicileri büyük organizasyonların ev sahiplerini yıllar öncesinden açıkladıklarından, tesisleşme ve alt yapılar adına o ülkede ciddi yatırımlar yapmak için yeterli zaman kalmaktadır. Şehirlerin altyapısı, ulaşım ağı, rekreasyon alanları gibi önemli ve kalıcı projeler bu süre zarfında planlanıp, gerçekleştirilebilir. Büyük spor organizasyonları özellikle metro ağı ve deniz ulaşımı projelerini gerçekleştirmek adına önemli bir neden olmaktadır.

Dünyadaki eğilime göre, SMS (Kısa Mesajlaşma Hizmeti) kullanımı sesli iletişimin önüne geçmektedir ve arkasından data servisleri gelmektedir. Spor organizasyonları esnasında, mobil pazarlama kampanyaları, SMS ve MMS (Mobil Çoklu Ortam Mesajlaşma Hizmeti) hizmetlerini kullanacaktır. Önümüzdeki yıllarda 4.5G teknolojisi ile Mobil TV ve Mobil Sosyal A $\breve{g}$ hizmetlerinin artması beklenmektedir.

Büyük spor organizasyonlarına ev sahipliği yapmak, telekomünikasyon alanında büyük uğraşlar gerektirebilir ama beraberinde fırsatlar da getirebilir. Müsabakalar sırasında telekomünikasyon şirketlerinin başarısı; medya çalışanları, Yerel Organizasyon Komitesi, seyirciler ve genelde tüm 
topluma verecekleri hizmetin uygunluğu ve kalitesi ile belli olacaktır. Dünyada sporu yöneten belli başlı örgütler (IOC, FIFA, FIBA vb.) ev sahipliği için değerlendirmelerini yaparken önemli teknolojik isteklerde bulunmaktadırlar. Devlet ve özel sektör işbirliği ile, yüzbinlerce insanın akın ettiği şehirlerde telekomünikasyon konusunda önemli ve yeni teknolojiye haiz alt yapı yatırımları da yapılacaktır. Fransa'daki 1998 Dünya Kupası digital veri transferini tetiklemiş, Almanya'daki 2006 Kupası ise TV ve cep telefonlarının uyumuna öncülük etmiştir. Sırada akıllı telefon üreticilerinin full HD ve 3D multimedya paketlerini iletecek cihazlar imal etmeleri vardır. Planlamalarda ise sadece trafik yükü, band genişliği ve kullanıcı özellikleri değil, teknolojik gelişim ile birlikte ortaya çıkabilecek sorun ve tehditler de göz önünde tutulmalıdır.

İleriye Dönük Kalıcı Tesisler: Büyük ölçekli spor organizasyonları bir şehrin genel profilini kesinlikle değiştirmektedir (ARUP, 2014). Yoğun kamuoyu ilgisi, zorlu ekonomik koşullar ve görünürlügün sosyal medya ile zirve yaptığı bir ortamda, başarılı bir dosya hazırlayarak oyunlara ev sahipliği yapma hakkının kazanılması ve ardında da organizasyonun başarı ile gerçekleşmesi, ortaya spora uzun süre hizmet edecek miraslar bırakmaktadır. Müsabakaların gerçekleşeceği modern tesisler bulunduğu bölgenin değişim ve gelişimine de katkı sağlamalıdır. Dijital teknolojilerin spor vasıtasıyla uygulanması bir beklenti değil, bir öncelik ve zorunluluk olarak görülmelidir. Ne yazik ki hala, bazı proje ihalelerinde hiç deneyimsiz mimarlar en ucuz teklif mantığıyla salon/stadyum proje yarışmalarını kazanmakta ve sonrası gelecek nesiller için felaket olmaktadır. Bütün bu nedenlerle, tesis mimari çizimleri yapılırken gelecekteki kullanıcıların (işletmeci ve sporcu) amaçları da düşünülerek yenilikçi ve esnek planlama yapılması, organizasyon teknik spesifikasyonları ile sonraki nesillerin beklentilerinin örtüştürülmesi gerekir.

\section{Dezavantajlar}

Büyük spor organizasyonlarına ev sahipliği yapmanın dezavantajları; yüksek maliyet, tesislerin verimsiz-kısa dönem kullanımı, yüksek güvenlik maliyetleri, başarısızlık halinde olası olumsuz imaj, bölgede yaşayanların rahatsızlığı, fiyat artışları bakımından incelenmiştir.

Yüksek maliyet: Büyük spor organizasyonları için yapılan yatırımların ve genel maliyetlerin oyunlar sırasında karşılanmasının mümkün olamayacağı artık bilimsel bir gerçektir. Rosenblum (2009), büyük organizasyonlar için harcanan yüksek miktarların sosyal yardımlar ve sağlık yatırımlarına yönlendirilmesinin daha iyi olacağını, üstelik finansal, sosyal ve politik alanlarda somut/ölçülebilir pozitif getirileri olacağını öne sürmektedir. Spor ekonomisti Zimbalist (2015), büyük bedeller harcanarak organize edilen turnuvaların 2014 Dünya Kupası öncesi (bütçe yaklaşık 20 Milyar Dolar) Brezilya'daki gibi büyük infial ve protestolara neden olacağını öne sürmektedir. 2008'de Pekin'de organize edilen Yaz Olimpiyatları yaklaşı 42 Milyar Dolarlık maliyeti ve Sochi'de düzenlenen 2014 Kış Olimpiyatları yaklaşık 50 Milyar Dolarlık bütçesi ile bu tür büyük spor organizasyonlarının mali tablolarına çok kötü birer örnek olmuşlardır. 2022 Futbol Dünya Kupası organizasyonunu alan Qatar'da bütçe 200 Milyar Dolar olarak belirlenmiştir, nedeni de yaz aylarındaki yüksek sıcaklık seviyeleri nedeniyle tüm stadyumlar klimatize edilecektir Alt yapıları kuvvetli ve mali denetimleri hassas olan gelişmiş ülkelerde harcamaların daha düşük seviyelerde 
gerçekleşmesi beklenmelidir. Nitekim, 2012'deki Londra Olimpiyatlari, beklenmedik güvenlik kalemi artışlarına rağmen, 11 Milyar Dolarlık harcama ile çok başarılı şekilde gerçekleşmiştir. Dolayısıyla kötü örneklerden yola çıkarak büyük spor organizasyonlarının küçülmesini veya aday olunmamasını istemek doğru değildir.

Tesislerin verimsiz-kısa dönem kullanımı: Büyük spor organizasyonları için inşa edilen tesislerin pek azı takip eden dönemlerde verimli olarak kullanılabilmektedir. 500 Milyon Dolar harcanarak 2008 Olimpiyatları için yapılan ve 'Bird's Nest' olarak adlandırılan 80.000 kişilik stadyum bugün Pekin'de sadece turizm turlarına ev sahipliği yapmaktadır. 2014 için Brezilya'da inşa edilen stadyumlardan bir tanesinin tutuklama kampı yapılması önerilmiştir. Mevcut alt yapı ve tesisleri maksimum kullanma adına 2020 Futbol Avrupa Kupasının 13 şehirde oynanması UEFA tarafından tartışılmaktadır (Woodhouse-Ledermann, 2015). Tesislerin atıl kalma olasılığının önüne dikkatli bir planlama ile geçilebilir. Buna en güzel örnek olarak; 2012 Londra Olimpiyatları sonrası atletlerin konakladığı olimpiyat köyünün apartman daireleri olarak satılması ve basketbol müsabakalarının oynandığı 12.000 kişilik salonun sökülebilir şekilde dizayn edilerek İngiltere’nin ihtiyaç duyulan herhangi bir yöresine monte edilebilir olması verilebilir.

Yüksek güvenlik maliyetleri: 1972'den beri terör, şiddet ve büyük spor organizasyonları arasında bir ilişki oluşmuştur (Toohey ve Taylor, 2008). Teröristlerin yüksek medya ilgisi ve yayını olan organizasyonları seçtiği bilinmektedir. Büyük spor organizasyonları da canlı televizyon yayınları ile büyümekte ve ilgi giderek artmaktadır. Teröristlerin de saldırı amacıyla yüksek toplanımlı yerleri, salonları, stadyumları ve kitle ulaşım araçlarını seçmeleri bu nedenledir. Terör ve yaratttı̆̆ 1 korku, giderek spor organizasyonlarını teslim almaktadır (Hassan ve Mitra, 2014). 9/11'den beri terör tehditleri karşısında güvenlik önlemleri giderek artmakta, organizatör federasyon, ev sahibi şehir ve ülkeler risk yönetimine çok daha fazla önem vermektedirler. Polis kuvvetleri ve özel güvenlik personeli salon ve tesislere girişte detaylı arama yapmakta, biletsiz ve akreditasyonsuz kişilerin içeri girişlerini engellemektedirler. Kişi beraberinde tesislere sokulacak maddeler sınırlanmıştır. Ayrıca, tesislerin etrafında bir güvenlik çemberi oluşturmak artık çok kullanılan bir yöntemdir. Güvenlik hizmetlerinin ne kadar ciddi maliyetler getirdiğine en iyi örnek 2012 Londra Olimpiyatları'dır. 2010'da Organizasyon Komitesi tarafından hazırlanan bütçede 44 Milyon Dolar olarak gözüken tesis koruma hizmetleri, özel sektörün yetersiz kalması sonucu asker ve polisin devreye girmesini gerektirmiş, harcamalar 777 Milyon Dolar olarak gerçekleşmiştir.

Başarısızlık halinde olası olumsuz imaj: Büyük spor organizasyonlarına ev sahipliği yapmak müsabakaların oynandığı bölgelere şehircilik açısından bir düzen ve iyileşme getirmelidir. Organizasyonu almak için sadece sportif başarı ve prestij düşünülmemeli, gerekli araştırmalar sonucunda toplumun her kesiminin desteği alınmalı, organizasyon; ulaşım, iletişim, çevre kirliliği vb. konularda atılım yapmak için bir araç olarak görülmelidir. Yerel yaşam şartlarının ağırlaşması, doğaya özensizlik, yeteneksiz ve kapasitesi sınırlı organizasyon komiteleri oluşturulması, şeffaf olmayan uygulama ve harcamalar, yolsuzluk, bütçelerin çok ve gereksiz aşılması, yerel yönetimlerin ciddi borç altına girmesi gibi faktörler kitlelerin tepkisini çekecektir. Hele başarısız sonuçlardan sonra organizasyon için harcanmış kaynakların çok daha önemli eğitim ve sağlık konularında harcanabileceği algısı topluma hakim olursa itirazlar protestolara bile dönüşebilir. 
Uluslararası boyutta ise organizasyon komitelerinin önemi ve birikimleri öne çıkmaktadır. Herhangi bir aksaklık halinde, delegasyonlar, medya mensupları, sporcuların şikayetleri kötü reklam olarak ev sahibi şehir/ülkenin dosyasına girecektir.

Bölgede yaşayanların rahatsızlığı: Alınan organizasyon için yeni tesisler ve alt yapı inşaatları söz konusu ise bölgede yaşayan insanların rahatsız edilmesi veya o bölgeden topluca ayrılmaya zorlanmaları söz konusu olabilir. Cenevre merkezli Centre on Housing Rights and Eviction raporuna göre, 1988'de Seoul'de 720.000 kişi, 2008'de 1,25 milyon Çin'li evlerinden ayrılmaya zorlanmışlardır (Dimeo, 2013). Büyük spor organizasyonları sadece elit bir sınıfın kazanç sağladığı, fakir kitlelerin kayıplara zorlandığı olaylar şekline dönüşmemelidir (Blumert, 2012). Dünya Şampiyonaları, Formula One, Olimpiyatlar gibi organizasyonlardaki yanlış tesis yeri seçimleri, baştan savma şehircilik projeleri, yetersiz altyapılar, yörenin gerçek ihtiyacı olan yatırımları ihmal etme huzursuzluğa neden olabilir. Geçici çözümler hiç bir zaman akıllı bir planlamanın önüne geçmemelidir (Smith, 2012). Beklentiler büyük olmasına karşın hedefine ulaşamayan 'gönüllü' programları da yörede hayal kırıklığı yaratabilir (Smith, 2006). Ücretli olsun veya olmasın, yüksek eğitim (ve çoğunlukla yabancı dil bilgisi) düzeyi beklentisi nedeniyle bölge sakinlerinin istihdam edilmemesi rahatsızlık yaratacaktır.

Fiyat Artışları: Evlerinden ayrılmak zorunda kalan insanlara ek olarak, toplumun bir borç sarmalına girmesi, yüksek enflasyon, yerel fiyatların artması, ithalattaki yükseliş gibi faktörler büyük spor organizasyonlarını takip edebilir. Geçici olarak tanımlanabilecek otel oda fiyat artışlarından ayrı olarak en büyük fiyat artışı gayrimenkullerde yaşanacaktır. Atina Olimpiyatları Yunanlılara o zamanın kurlarına göre 11 Milyar Dolara mal olmuş ve en pahalı Olimpiyat olarak kayıtlara geçmiştir (Malkoutzis, 2012). Bu büyük spor organizasyonun Yunan vatandaşlarına getirdiği vergi yükü 8 Milyar Dolar olarak hesaplanmaktadır. Bu rakamlara yeni havaalanı ve metro sistemi gibi ek projeler dahil değildir. 2004 yılında Gayrisafi Yurtiçi Hasılasının \% 6,1’i olan borç miktarı 2012 yılında \% 165,3’e ulaşmıştır. Bütün bu ekonomik kötü gidişi Olimpiyatlara bağlamak doğru olmamakla birlikte tetikleyici etkisinin olduğu da bir gerçektir.

\section{SONUÇ}

Olimpiyatlar, Futbol Dünya ve Avrupa Şampiyonaları, Grand Slam Tenis müsabakaları, Formula One yarışmaları, basketbol, voleybol, handball gibi ana sporların Dünya ve Avrupa Şampiyonaları her yaştan seyirci ve izleyicilerin büyük ilgisini çekmektedir. Bu tür müsabaka ve yarışmaları organize etmek isteyen şehir ve ülkelerin sayısı giderek artmaktadır. Bir ülkenin büyük bir spor organizasyonuna ev sahipliği yapması çok önemli bir olaydır; o ülke, şehir ve vatandaşları için gurur kaynağı olacaktır. Her ne kadar organizatör ülkenin takım ve sporcularının sahadaki başarısı maçların/turnuvanın popülaritesini -özellikle gelişmekte olan ülkelerde- doğrudan etkilese de, bu tip organizasyonlar tüm dünyanın izlediği, tanınmış atletlerin oynadığı/yarıştı̆̆1, rekorların kırıldığı, sürpriz sonuçların alındığı sıra dışı spor olaylarıdır.

Büyükbir spor organizasyonuna ev sahipliği yapma hakkı elde edildikten sonra, Yerel Organizasyon 
Komitesi'nin kurulmasıyla beraber ilk yapılacak işlerden biri, ilgili proje biriminin oluşturulması, proje yönetimi prensiplerinin uygulanması ve detaylı bir risk yönetim planının hazırlanmasıdır. Sonuç olarak; ne yaptığını bilen, organize ve birikimli Yerel Organizasyon Komiteleri bu sorunun altından başarıyla kalkabilirler. Her büyük spor organizasyonunun kendine mahsus özellikleri, bir başlangıç ve sonu olduğundan, yapılacak çalışma bir çok alt projeyi içeren büyük bir proje olacaktır.

Büyük spor organizasyonlarının net etkilerini saptayabilmek kolay olmamakla birlikte, bu çalışmada belirtilen avantajları ve dezanvantajları gözönüne alındı̆̆ında potansiyel getirilerinin çok daha fazla olduğu gözlenmektedir. 


\section{KAYNAKLAR}

Abiodun, O.R. (2011). The Significance of Sponsorship as a Marketing Tool in Sport Events. Degree Thesis, International Business. Arcada University, Helsinki. [Available at: http://www.theseus.fi/bitstream/ handle/10024/24945/Student_Abiodun_Oladunni.pdf], Retrieved on: February 10, 2016.

ARUP (2014). Major Events and Venues: . [Available at: http://publications.arup.com/publications/m/ major_events_and_venues], Retrieved on: February 10, 2016.

Baron, D. P. (2003). Business and Its Environment. Englewood Cliffs, NJ: Prentice Hall.

Blumert, J. (2012). Home Games; Legal Issues Concerning the Displacement of Property Owners at the Site of Olympic Venues. Cardozo Journal of International \& Comparative Law, 21(1), 153-195.

Coalter, F. (2004). Stuck in the Blocks? A sustainable sporting legacy. In A. Vigor, M. Mean \& C. Tims (Eds.). After the Goldrush: A sustainable Olympics for London (pp. 91-108). London: ippr and Demos.

Corbett, R. (2002). Risk Management for Sport Organizations and Sport Facilities. August 23, 2002. [Available at: http://www.sportlaw.ca/2002/08/risk-management-for-sport-organizations-andsport-facilities/] Retrieved on: April 15, 2016.

Brandwatch (2013). Sponsorship and Social Media: A Brandwatch Analysis of Barclays Premier League Sponsorship. [Available at: https://14415-presscdn-0-52-pagely.netdna-ssl.com/wp-content/ uploads/2013/05/Brandwatch-Barclays-Premier-League-Report-May-2013.pdf], Retrieved on: February 10, 2016.

Dimeo, P. (2013). Hosting Major Sports Events: Hidden Costs and Policy Dilemmas. Global Policy, July 5, 2013. [Available at: http://www.globalpolicyjournal.com/blog/05/07/2013/hosting-major-sportsevents-hidden-costs-and-policy-dilemmas], Retrieved on: February 10, 2016.

Gray, C. F. \& Larson E. W. (2010). Project Management: The Managerial Process. 5th Edition. New York: McGraw-Hill.

Hassan, D. \& Mitra, S. (2014). The Olympic Games: Meeting New Global Challenges. United Kingdom: Routledge.

Ibrahim, H. \& Almarshed, S.O. (2014). Sporting Event as a Corporate Social Responsibility Strategy. Procedia Economics and Finance, 11, 3-14.

IOC (International Olympic Committee). (2012). Barcelona "Totally Transformed" by Hosting 1992 Olympic Games. July 12, 2012 [Available at: https://www.olympic.org/news/barcelona-totallytransformed-by-hosting-1992-olympic-games]. Retrieved on February 22, 2016.

Jennings,W. (2013).Risk and the Mega-Event Industry. May27,2013 [Available at: http://cgd.swissre.com/ risk_dialogue_magazine/Mega_events/Risk_and_the_MegaEvent_Industry.html\#The Risk of mega events: from the prosaic to the extreme]. Retrieved on: May 4, 2016.

Loepkey, B. \& Parent, M. (2009). Risk Management Issues in Large-Scale Sporting Events: a Stakeholder Perspective. European Sport Management Quarterly 9(2):187-208 June, 2009.

Malkoutzis, N. (2012). How the 2004 Olympics Triggered Greece's Decline. Bloomberg, August 3, 2012. [Available at: http://www.bloomberg.com/news/articles/2012-08-02/how-the-2004-olympicstriggered-greeces-decline], Retrieved on: February 10, 2016.

Matheson, V. A. \& Baade, R. A. (2004). Mega-Sporting Events in Developing Nations: Playing the Way to Prosperity?. The South African Journal of Economics, 72(5), 1085-1096.

Matos P. (2006). Hosting Mega Sports Events: A Brief Assessment of Their Multidimensional Impacts. The Copenhagen Conference on the Economic and Social Impact of Hosting Mega Sports Events. Copenhagen: Copenhagen Business School.

Nooij, M., Van den Berg, M. \& Koopmans, C. (2013). Bread or games? A social cost-benefit analysis of the World Cup bid of the Netherlands and the winning Russian bid. Journal of Sports Economics, 14 (5), 521-545. 
Ritchie, B. W., Shipway, R. \& Cleeve, B. (2009). Resident Attitudes Towards Mega-Sporting Events: A Non-Host City Perspective of the 2012 London Olympic Games. Journal of Sport and Tourism, 14(2-3), 143-167.

Rosenblum, S. (2009). The Impact of the Summer Olympics on its Host City: The Costs Outweigh the Tangible Benefits. Honors Projects in History and Social Sciences. Paper 5. Bryant University: Bryant, LIU Brooklyn. [Available at: http://digitalcommons.bryant.edu/honors_history/5], Retrieved on: February 10, 2016.

Röfner, A. \& Müller, M. (2009). Critical Success Factors of International Sport Events from the Perspective of Project Management. Umea University School of Business, Master in Management.

Silvestre, G. (2009). The Social Impacts of Mega-Events: Towards a Framework. Esporte e Sociedade, 4(10), $1-26$.

Smith, A. (2006). After the Circus Leaves Town: The Relationship between Sports Events, Tourism and Urban Regeneration. In M. K. Smith (Ed.) Tourism, Culture and Regeneration (pp. 85-100). Wallingford. UK: CABI Publishing.

Smith, A. (2012). Events and Urban Regeneration: The Strategic Use of Events to Revitalise Cities. New York: Routledge.

Toohey, K. \& Taylor, T. (2008). Mega Events, Fear, and Risk: Terrorism at the Olympic Games. Journal of Sport Management, 22, 451-469.

Walters, G. \& Chadwick, S. (2009). Corporate Citizenship in Football; Delivering Strategic Benefits through Stakeholder Engagement. Management Decision. 47(1), 51-66.

Woodhouse-Ledermann, L. (2015). The white elephant - What mega sporting events leave behind. July 8, 2015. [Available at: http://www.sportanddev.org/en/newsnviews/news/?12702/1/The-WhiteElephant---what-mega-sporting-events-leave-behind], Retrieved on: February 10, 2016.

Zimbalist, A. (2015). Circus Maximus: The Economic Gamble Behind Hosting the Olympics and the World Cup. Washington, D.C.: Brookings Institution Press. 